\title{
Genetic structure of Trypanosoma cruzi in American continents: special emphasis on sexual reproduction in Central America
}

\author{
H. HIGO ${ }^{1 *}$, T. YANAGI ${ }^{2}$, V. MATTA ${ }^{3}$, T. AGATSUMA ${ }^{4}$, A. CRUZ-REYES ${ }^{5}$, N. UYEMA ${ }^{6}$, \\ C. $\mathrm{MONROY}^{3}$, H. KANBARA ${ }^{2}$ and I. TADA ${ }^{1}$ \\ ${ }^{1}$ Department of Parasitology, Graduate School of Medicine, Kyushu University, Maidasi 3-1-1, Higashiku, Fukuoka \\ 812-8582, Ұapan \\ ${ }^{2}$ Department of Protozoology, Institute of Tropical Medicine, Nagasaki University, Fapan \\ ${ }^{3}$ Facultad de Ciencias Quimicas y Farmacia, Universidad Nacional de San Carlos, Guatemala \\ ${ }^{4}$ Department of Environmental Health Science, Kochi Medical School, Fapan \\ ${ }^{5}$ Instituto de Biologia, Universidad Nacional Autonoma de Mexico, Mexico \\ ${ }^{6}$ Laboratorio de Microbiologia, Facultad de Medicina, Universidad San Martin de Porres, Peru
}

(Received 13 December 1999; revised 5 April 2000; accepted 7 April 2000)

\section{SUMMARY}

Isozyme analysis (12 enzymes: 14 loci) was conducted on 99 isolates of Trypanosoma cruzi: 77 from Guatemala, 5 from Mexico and 17 from South American countries. Analyses of 4 population-genetic indices were undertaken to assess the possibility of genetic exchange occurring among Guatemalan isolates. The results provide evidence for a degree of genetic exchange occurring among isolates from this relatively small geographical area. Previous studies of population genetics on T. cruzi might have failed to detect this phenomenon because they tended to use isolates originating far from one another, rendering gene exchange unlikely for geographical reasons. Phylogenetic data, presented here, show considerable differences in genetic structure between Central and South American isolates, suggesting that different biological and clinical properties might be expected. For example, there are differences in clinical syndromes between Central and South America, a situation discussed further here.

Key words: Trypanosoma cruzi, genetic recombination, Chagas' disease, isozyme, phylogeny, pathogenicity.

\section{INTRODUCTION}

Chagas' disease, caused by Trypanosoma cruzi, is a serious public health problem in Latin America, affecting between 16 and 18 million people (Dias, 1992). However, many biological questions of epidemiological significance remain unanswered. For example, little is known about the reproductive biology of the species. If populations are mainly clonal, which has been shown by some researchers (Tibayrenc \& Ayala, 1988; Tibayrenc, Kjellberg \& Ayala, 1990; Ayala, 1993; Tibayrenc, 1995), then specific genetic and epidemiological attributes will arise and be maintained independently in different lineages. If sexual reproduction can occur, a possibility recently claimed by some researchers (Lewicka et al. 1995; Bogliolo, Lauria-Pires \& Gibson, 1996; Carrasco et al. 1996), even to a limited extent, then those attributes can be recombined to co-occur in the same individual organism. From the point of view of strain-specific PCR diagnosis and chemotherapy, this is a more worrying situation.

* Corresponding author: Department of Parasitology, Graduate School of Medicine, Kyushu University, Maidasi 3-1-1, Higashiku, Fukuoka 812-8582, Japan. Tel: +8192642 6118. Fax: +81926426115.

E-mail: hirohigo@parasite.med.kyushu-u.ac.jp
Previous studies investigating reproductive biology in $T$. cruzi have often examined isolates originating very far from one another. Thus, it is not surprising that they have failed to find evidence for gene exchange. In our previous isozyme study (Higo et al. 1997), we examined the degree of genetic exchange among a small number of isolates from Guatemala by using 2 population-genetic indices (1) deviation from Hardy-Weinberg equilibrium and (2) the differences between observed and expected heterozygosity. The former index suggested clonal reproduction. However, the latter did not. In the present study, we repeated the previous analyses and added a further 2 indices in an investigation of a far larger collection (75) of isolates from Guatemala. Being a small country, where local movements of infected people or reservoir hosts could bring different strains of T. cruzi into sympatry, Guatemala provided a very suitable location for this work. Examination of numerous sympatric (or nearly so) isolates should detect gene exchange if this is happening with at least moderate frequency. We also constructed a phylogenetic tree to determine the relationships among our isolates. This indicated that 2 Guatemalan isolates were extremely different genetically from the majority of other Guatemalan isolates, so they were excluded from the population 
Table 1. Geographical and host origin, and zymodemes of isolates of Trypanosoma cruzi

\begin{tabular}{|c|c|c|c|c|}
\hline Isolate & $\begin{array}{l}\text { No. of } \\
\text { isolates }\end{array}$ & Zymodeme & Host & Locality \\
\hline $\begin{array}{l}\text { H6-8, H10, HN4004, } \\
\text { SM53, SM249, SM392 }\end{array}$ & 8 & $Z-1$ & Human & Santa Rosa, Guatemala \\
\hline H18, H31 & 2 & $Z-1$ & Human & Zacapa, Guatemala \\
\hline $\begin{array}{l}\text { TM1-4, TM6-7, TM9-13, } \\
\text { TM15-16, TM18-21, } \\
\text { TM23, TM25-39, } 171\end{array}$ & 34 & $\mathrm{Z}-1$ & Triatoma dimidiata & Santa Rosa, Guatemala \\
\hline MAR5, MAR6 & 2 & $Z-1$ & Triatoma dimidiata & Guatemala, Guatemala \\
\hline VER1, VER3-6 & 5 & $Z-1$ & Opossum & Mexico \\
\hline $\mathrm{VC}$ & 1 & $\mathrm{Z}-1$ & Triatoma nitida & Guatemala, Guatemala \\
\hline RM1, RM5 & 2 & $Z-1$ & Rhodonius prolixus & Zacapa, Guatemala \\
\hline MTM1 & 1 & $\mathrm{Z}-1$ & Wild rat & Santa Rosa, Guatemala \\
\hline G & 1 & $\mathrm{Z}-1$ & Unknown & Guatemala \\
\hline $\mathrm{H} 23$ & 1 & $Z-2$ & Human & Zacapa, Guatemala \\
\hline TM8, TM14, 172 & 3 & $\mathrm{Z}-2$ & Triatoma dimidiata & Santa Rosa, Guatemala \\
\hline $\begin{array}{l}\mathrm{H} 13.2, \mathrm{H} 14-15, \mathrm{H} 21, \\
\mathrm{H} 25, \mathrm{H} 28-30\end{array}$ & 8 & $Z-3$ & Human & Zacapa, Guatemala \\
\hline TM17 & 1 & $Z-3$ & Triatoma dimidiata & Santa Rosa, Guatemala \\
\hline RM3, RM4 & 2 & $Z-3$ & Rhodonius prolixus & Zacapa, Guatemala \\
\hline MTM2 & 1 & $Z-3$ & Squirrel & Guatemala, Guatemala \\
\hline ТМ22, ТМ24 & 2 & $Z-4$ & Triatoma dimidiata & Santa Rosa, Guatemala \\
\hline $\mathrm{H} 12$ & 1 & $Z-5$ & Human & Santa Rosa, Guatemala \\
\hline $\mathrm{H} 27$ & 1 & Z-5 & Human & Zacapa, Guatemala \\
\hline H17 & 1 & Z-6 & Human & Santa Rosa, Guatemala \\
\hline $\mathrm{H} 22, \mathrm{H} 26$ & 2 & $\mathrm{Z}-7$ & Human & Zacapa, Guatemala \\
\hline $\mathrm{H} 24$ & 1 & Z-8 & Human & Santa Rosa, Guatemala \\
\hline $\mathrm{HN} 274$ & 1 & $Z-9$ & Human & Santa Rosa, Guatemala \\
\hline $\mathrm{H} 20$ & 1 & Z-9 & Human & Zacapa, Guatemala \\
\hline $\mathrm{PH} 1, \mathrm{PH} 2$ & 2 & $Z-9$ & Human & Peru \\
\hline Colombia & 1 & $Z-10$ & Human & Colombia \\
\hline $\mathrm{CL}$ & 1 & $Z-10$ & Insect vector & Brazil \\
\hline P'TM1-4 & 4 & $Z-11$ & Triatoma infestans & Peru \\
\hline 119 & 1 & $Z-12$ & Opossum & Ecuador \\
\hline SX10/4, SX10/7 & 2 & $Z-13$ & Human & Brazil \\
\hline ESM3 & 1 & $Z-14$ & Human & Brazil \\
\hline $\mathrm{Y}$ & 1 & $Z-15$ & Human & Brazil \\
\hline GS, LO, RF & 3 & $Z-15$ & Human & Paraguay \\
\hline Tul-L & 1 & $Z-15$ & Unknown & Chile \\
\hline
\end{tabular}

genetic analysis. All Guatemalan isolates used for the analysis of genetic exchange therefore belonged to a single phylogenetic Group (Group 1) identified in our previous study (Higo et al. 1997).

\section{MATERIALS AND METHODS}

\section{Parasites}

A total of 99 isolates of $T$. cruzi was used in this study, 82 of these from Guatemala and Mexico, and 17 from South America (see Table 1 for details). Isolation of parasites from humans and insects, and sample preparation for isozyme analysis were done according to the methods of Higo et al. (1997).

\section{Sample preparation and isozyme analysis}

Buffer systems, electrode conditions and the enzymatic staining of the gel slices for isozymes followed the modified methods of Agatsuma \& Habe (1986) and Shaw \& Prasad (1970). Twelve enzymes, AK, CK, DIA, GAPD, GPI, IDH, MDH, ME, MPI, PEP, 6PGD, PGM, were investigated (Higo et al. 1997).

\section{Calculation of genetic distances and construction of a dendrogram}

As T. cruzi is considered to be at least partially clonal in reproduction (Tibayrenc \& Ayala, 1988), it is not possible to calculate the genetic distances among the populations by assuming random mating. So we assigned all the isolates into zymodemes according to the pattern of zymograms. Nei's genetic distances (Nei, 1987) for each pair of zymodemes were calculated by GENDIST program in PHYLIP package version 3.572 (Felsenstein, 1993). A dendrogram was drawn from the matrix of genetic distances by the unweighted pair-group method 
Table 2. Zymodemes of Trypanosoma cruzi generated from isozyme analyses

\begin{tabular}{|c|c|c|c|c|c|c|c|c|c|c|c|c|c|c|}
\hline Zymodeme & AK1 & AK2 & $\mathrm{CK}$ & DIA & GAPD & GPI & IDH & MDH & ME2 & MPI & PEP1 & PEP2 & 6PGD & PGM \\
\hline$Z-1$ & $1 / 1$ & $1 / 1$ & $1 / 1$ & $1 / 1$ & $1 / 1$ & $4 / 4$ & $3 / 3$ & $1 / 1$ & $2 / 2$ & $1 / 3$ & $3 / 3$ & $3 / 3$ & $1 / 1$ & $1 / 1$ \\
\hline$Z-2$ & $1 / 1$ & $1 / 1$ & $1 / 1$ & $1 / 1$ & $3 / 3$ & $4 / 4$ & $3 / 3$ & $1 / 1$ & $2 / 3$ & $3 / 3$ & $3 / 3$ & $3 / 3$ & $1 / 1$ & $1 / 1$ \\
\hline Z-3 & $1 / 1$ & $1 / 1$ & $1 / 1$ & $1 / 1$ & $2 / 2$ & $4 / 4$ & $3 / 3$ & $1 / 1$ & $2 / 3$ & $3 / 3$ & $3 / 3$ & $3 / 3$ & $1 / 1$ & $1 / 1$ \\
\hline$Z-4$ & $1 / 1$ & $1 / 1$ & $1 / 1$ & $1 / 1$ & $3 / 3$ & $4 / 4$ & $3 / 3$ & $1 / 1$ & $2 / 2$ & $3 / 3$ & $3 / 3$ & $3 / 3$ & $1 / 1$ & $1 / 1$ \\
\hline Z-5 & $1 / 1$ & $1 / 1$ & $1 / 1$ & $1 / 1$ & $3 / 3$ & $4 / 4$ & $3 / 3$ & $1 / 1$ & $2 / 4$ & $1 / 3$ & $3 / 3$ & $3 / 3$ & $1 / 1$ & $1 / 1$ \\
\hline Z-6 & $1 / 1$ & $1 / 1$ & $1 / 1$ & $1 / 1$ & $2 / 2$ & $4 / 4$ & $3 / 3$ & $1 / 1$ & $2 / 4$ & $1 / 3$ & $3 / 3$ & $3 / 3$ & $1 / 1$ & $1 / 1$ \\
\hline$Z-7$ & $1 / 1$ & $1 / 1$ & $1 / 1$ & $1 / 1$ & $3 / 3$ & $4 / 4$ & $3 / 3$ & $1 / 1$ & $2 / 3$ & $1 / 3$ & $3 / 3$ & $3 / 3$ & $1 / 1$ & $1 / 1$ \\
\hline Z-8 & $1 / 1$ & $1 / 1$ & $1 / 1$ & $1 / 1$ & $2 / 2$ & $4 / 4$ & $3 / 3$ & $1 / 1$ & $2 / 3$ & $1 / 3$ & $3 / 3$ & $3 / 3$ & $1 / 1$ & $1 / 1$ \\
\hline Z-9 & $1 / 1$ & $1 / 1$ & $0 / 0$ & $3 / 3$ & $6 / 6$ & $3 / 3$ & $1 / 1$ & $1 / 1$ & $1 / 1$ & $4 / 4$ & $1 / 1$ & $1 / 2$ & $0 / 0$ & $2 / 2$ \\
\hline Z-10 & $1 / 1$ & $1 / 1$ & $1 / 1$ & $1 / 1$ & $3 / 3$ & $4 / 4$ & $3 / 3$ & $1 / 1$ & $2 / 2$ & $1 / 3$ & $3 / 3$ & $3 / 3$ & $1 / 1$ & $1 / 1$ \\
\hline Z-11 & $1 / 1$ & $1 / 1$ & $1 / 1$ & $1 / 1$ & $6 / 6$ & $4 / 4$ & $3 / 3$ & $1 / 1$ & $2 / 2$ & $3 / 3$ & $3 / 4$ & $3 / 3$ & $1 / 1$ & $1 / 1$ \\
\hline Z-12 & $1 / 1$ & $1 / 1$ & $1 / 1$ & $1 / 1$ & $3 / 3$ & $4 / 4$ & $2 / 2$ & $1 / 1$ & $2 / 2$ & $1 / 1$ & $3 / 3$ & $6 / 6$ & $1 / 1$ & $1 / 1$ \\
\hline Z-13 & $1 / 1$ & $1 / 1$ & $1 / 1$ & $1 / 1$ & $4 / 5$ & $4 / 4$ & $3 / 3$ & $1 / 1$ & $2 / 2$ & $3 / 3$ & $2 / 2$ & $4 / 4$ & $1 / 1$ & $1 / 1$ \\
\hline Z-14 & $1 / 1$ & $1 / 1$ & $0 / 0$ & $2 / 2$ & $6 / 6$ & $1 / 1$ & $1 / 3$ & $1 / 1$ & $4 / 4$ & $2 / 2$ & $4 / 4$ & $5 / 5$ & $0 / 0$ & $2 / 2$ \\
\hline$Z-15$ & $1 / 1$ & $1 / 1$ & $0 / 0$ & $1 / 1$ & $6 / 6$ & $2 / 2$ & $1 / 3$ & $1 / 2$ & $4 / 4$ & $2 / 2$ & $4 / 4$ & $7 / 7$ & $0 / 0$ & $2 / 2$ \\
\hline
\end{tabular}

with arithmetic mean (UPGMA) (Nei, 1987) by using NEIGHBOR and DRAWGRAM program in PHYLIP. We performed 1000 bootstraps to estimate the significance of branching in the tree by SEQBOOT program in PHYLIP.

\section{Criteria for inferring clonality versus genetic exchange}

All 75 T. cruzi isolates from Guatemala belonging to Group 1 (see dendrogram below) were used in analyses to estimate the degree of genetic exchange occurring. As criteria of clonality, the following 4 indices were employed (1) the deviation of observed distribution of genotypes from the expected one based on the Hardy-Weinberg equilibrium with 3 loci, GAPD, ME2, MPI which were polymorphic among the Guatemalan population, (2) the difference between the expected value of heterozygosity $(\mathrm{He})$ and the observed one (Ho), (3) normalized coefficient of linkage disequilibrium which is expressed by the ratio of the coefficient of linkage disequilibrium to the corresponding maximum value in pairs of 3 loci, GAPD, ME2, MPI, and (4) the degree of association between loci examined (IA) which can be a generalized measure of linkage disequilibrium. Indices (1) and (2) were calculated by the same methods as Higo et al. (1997), indices (3) according to Ayala (1993). For indices (4) we followed Brown, Feldman \& Nevo (1980), Maynard Smith et al. (1993) and Stevens \& Tibayrenc (1996).

\section{RESULTS}

Of 12 enzymes examined, AK and PEP had 2 loci, indicated by the suffix 1 (faster electromorph) and 2 (slower electromorph) in Table 2. All of the other enzymes were encoded by 1 locus, so that in total 14 loci were identified. AK showed no variation among all the isolates. Five loci, GAPD, ME2, MPI, PEP1 and PEP2 varied among the isolates of Group 1, and all the other loci except AK varied between major phylogenetic groups.

Fifteen zymodemes were identified by isozyme analysis of the 99 isolates of $T$. cruzi: zymodemes 1-9 from Guatemala and Mexico, and zymodemes 10-15 from South America (Table 1). Table 2 shows the genotype of each zymodeme which was determined by the zymogram patterns. The dendrogram of relationships among isolates (Fig. 1) revealed 3 main lineages. The majority of Guatemalan, Mexican and some South American isolates formed Group 1. Two human isolates from Guatemala and 2 from Peru formed Group 2, and isolates obtained only from South America fell into Group 3.

No significant difference was shown with the locus ME2 when comparison was made between observed and expected gene frequencies. However, a significant deviation from the Hardy-Weinberg equilibrium was found for GAPD and MPI (Table 3). The expected value of heterozygosity $(\mathrm{He}=0 \cdot 087)$ was not different from the observed one $(\mathrm{Ho}=$ $0 \cdot 075)$. The ratio of linkage disequilibrium of combinations for 3 loci, GAPD, ME2 and MPI, were small for GAPD/ME2 and GAPD/MPI, being 0.171 and 0.45 respectively, but high $(0.8)$ for the other combination ME2/MPI (Table 4). The indices of association (IA) were $2 \cdot 016 \pm 0 \cdot 830$ for 75 isolates in Group 1 from Guatemala and $-0.401 \pm 0.593$ for 8 electrophoretic types (ETs) of zymodeme 1-8, indicating the possibility of genetic recombination by the value that is not significantly different from 0 for ETs (Maynard Smith et al. 1993). Of these results, the genetic exchange, possibly partially occurring, seems to be suggested by (1) the lack of deviation from the Hardy-Weinberg equilibrium at the locus ME2, (2) lack of difference between expected and observed heterozygosity, (3) deviation of the linkage disequilibrium coefficient $\left(\mathrm{D}^{\prime}\right)$ from a value of 1 for the locus pairs GAPD/ME2 and 


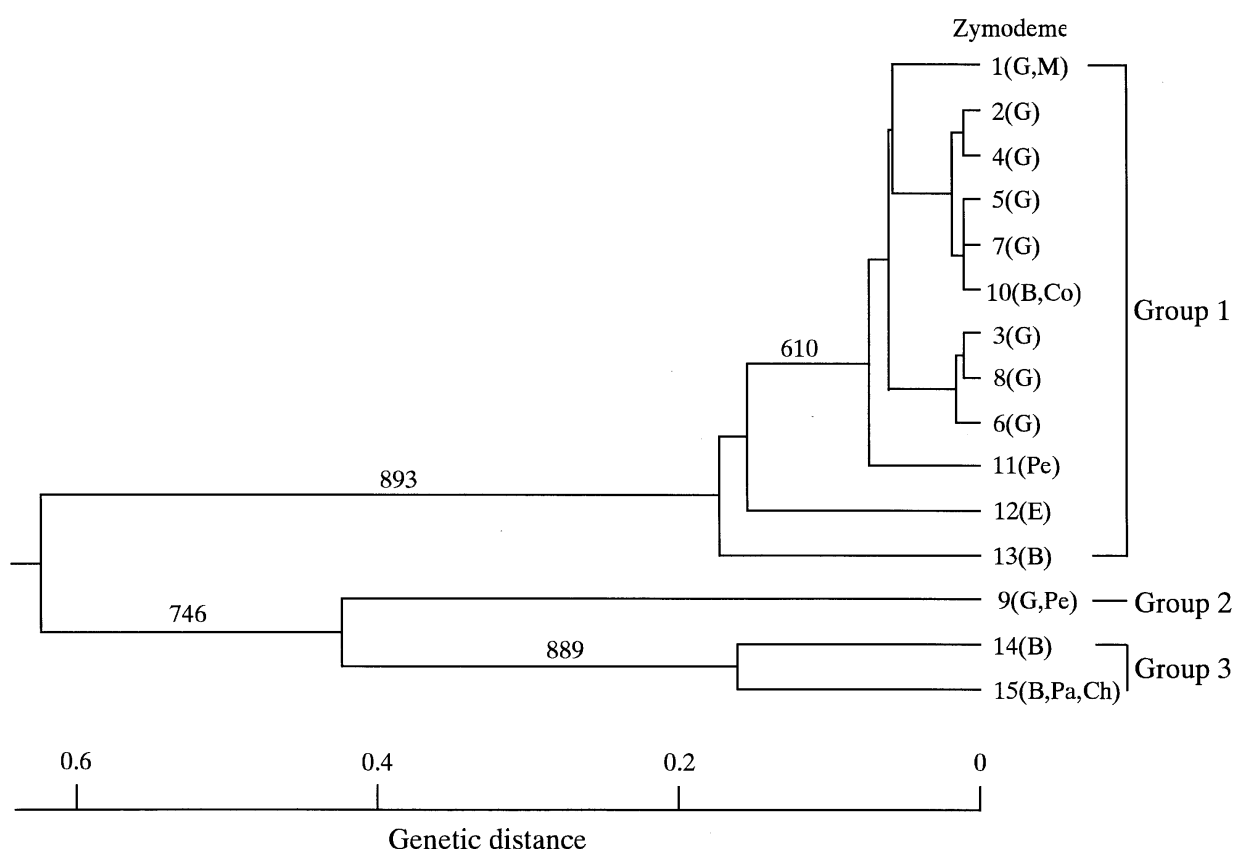

Fig. 1. Dendrogram drawn based on the matrix of genetic distances among 15 zymodemes of Trypanosoma cruzi using UPGMA. The figures on branches indicate the number of times that the branch was observed in 1000 bootstraps. Bootstrap values below 600 are not given. Abbreviations: B, Brazil; Ch, Chile; Co, Colombia; E, Ecuador; G, Guatemala; M, Mexico; Pa, Paraguay; Pe, Peru.

Table 3. Expected and observed distribution of genotype of Trypanosoma cruzi population from Guatemala

(The differences between observed and expected distributions were significant in GAPD and MPI $(P<0 \cdot 01)$, not in ME2 $(P>0 \cdot 05)$ by $\chi^{2}$ test. $\chi^{2}$ tests were calculated between 4 groups $(1 / 1,2 / 2+3 / 3+2 / 3,1 / 2,1 / 3)$ for GAPD, 3 groups $(2 / 2,3 / 3+4 / 4+2 / 4+3 / 4,2 / 3)$ for ME2 to prevent expected values from being less than 5 .)

\begin{tabular}{lllc}
\hline \hline \multirow{3}{*}{ Enzyme } & Genotype & Observed & Expected \\
\cline { 3 - 4 } GAPD & $1 / 1$ & 51 & $34 \cdot 68$ \\
& $2 / 2$ & 14 & $2 \cdot 623$ \\
& $3 / 3$ & 10 & $1 \cdot 327$ \\
& $1 / 2$ & 0 & $19 \cdot 074$ \\
& $1 / 3$ & 0 & $13 \cdot 566$ \\
ME2 & $2 / 3$ & 0 & $3 \cdot 73$ \\
& $2 / 2$ & 53 & $54 \cdot 571$ \\
& $3 / 3$ & 0 & $1 \cdot 21$ \\
& $4 / 4$ & 0 & $0 \cdot 03$ \\
& $2 / 3$ & 19 & $15 \cdot 25$ \\
MPI & $2 / 4$ & 3 & $2 \cdot 559$ \\
& $3 / 4$ & 0 & $0 \cdot 381$ \\
& $1 / 1$ & 0 & $10 \cdot 83$ \\
& $3 / 3$ & 18 & $28 \cdot 83$ \\
\hline \hline
\end{tabular}

GAPD/MPI, and (4) the value of IA for ETs not significantly different from 0 . However, the remaining results, deviations from the Hardy-Weinberg equilibrium at GAPD and MPI, the $\mathrm{D}^{\prime}$ value of nearly 1 for the pair of ME2/MPI, are as expected for clonal organisms.
Table 4. Linkage disequilibrium in Trypanosoma cruzi population from Guatemala

( $\mathrm{D}$ (obs) is the disequilibrium observed; $\mathrm{D}(\max )$ is the maximum value possible for the observed allelic frequencies; $\mathrm{D}^{\prime}$ indicates $\mathrm{D}(\mathrm{obs}) / \mathrm{D}(\max )$. $\mathrm{D}^{\prime}$ values of GAPD $\times$ ME2 and GAPD $\times$ MPI are much lower than 1.)

\begin{tabular}{llll}
\hline \hline Compared loci & $\mathrm{D}(\mathrm{obs})$ & $\mathrm{D}(\max )$ & $\mathrm{D}^{\prime}$ \\
\hline GAPD $\times$ ME2 & $0 \cdot 029$ & $0 \cdot 172$ & $0 \cdot 171$ \\
GAPD $\times$ MPI & $0 \cdot 031$ & $0 \cdot 073$ & $0 \cdot 425$ \\
ME $2 \times$ MPI & $0 \cdot 04$ & 0.05 & $0 \cdot 8$ \\
\hline \hline
\end{tabular}

\section{DISCUSSION}

Substantially clonal reproduction of $T$. cruzi has been shown in the natural population by isozyme and DNA analyses (Ayala, 1993; Tibayrenc, 1995; Tibayrenc \& Ayala, 1988; Tibayrenc et al. 1990). However, recent studies (Lewicka et al. 1995; Bogliolo et al. 1996; Carrasco et al. 1996), suggested the possibility of genetic exchange in T. cruzi using data from isozyme and DNA analyses. In the present study population genetic analyses did not show necessarily clonal reproduction in Guatemala, and suggest that genetic exchange may occur to some extent in this small geographical area. However, the divergences from Hardy-Weinberg equilibrium at loci for GAPD and MPI and the homozygous patterns of some polymorphic loci, especially GAPD, are indicative of clonality, suggesting that genetic exchange, if present, is at a low level. Even a low level of genetic exchange will permit recom- 
bination of any biological attributes and genetic markers such as sensitivity to drugs and PCR patterns for strain-specific diagnosis. Further population genetic studies of $T$. cruzi are necessary to assess the degree of clonality using many more populations.

To identify the genetic structure of Central American isolates and also to confirm the validity of Guatemalan isolates for the population genetic analyses of gene exchange, we constructed a dendrogram to show relationships among all available isolates. Many such studies on T. cruzi have been carried out by isozyme and DNA analyses in South America (Miles et al. 1984; Tibayrenc \& Ayala, 1988; DeLucad'oro et al. 1993; Lewicka et al. 1995). However, there have been many fewer studies on isolates from North and Central America. DeLeon et al. (1998) and Lopez-Olmos et al. (1998) reported many lineages of T. cruzi in Guatemala and Mexico by DNA and isozyme analyses, respectively. In the present study, a dendrogram based on isozyme analysis of 99 isolates showed almost the same features as that of Higo et al. (1997), except for an increase in the number of zymodemes. Group 1 consists of the majority of isolates (from humans, insects and reservoir hosts) from Guatemala, all the Mexican ones and those from northern countries of South America. Only 4 isolates were placed in Group 2 (2 patients from Peru and 2 from Guatemala). The isolates of Group 3 were found in humans, insect vectors and reservoirs from the southern regions of South America only. Group 1, distributed mainly in the northern part of Latin America, is quite distinct from the South American unique strain of Group 3.

Isozyme studies have indicated 3 main phylogenetic groups $(Z 1, Z 2, Z 3)$ on T. cruzi in South America (Carrasco et al. 1996; Miles et al. 1984; Tibayrenc \& Miles, 1983), and also recently the presence of 2 main lineages has been reported based on isozyme, RAPD and other DNA analyses (Tibayrenc, 1995; Oury et al. 1997; Gomes et al. 1998; Oliveira et al. 1998). Comparing the data of previous studies and ours with reference strains SX10 and ESM3, Groups 1 and 3 in the present study seem to correspond to $\mathrm{Z} 1$ and $\mathrm{Z} 2$ in the study of Miles et al. (1984) and Tibayrenc \& Miles (1983). Further data and analyses are also required to determine the correct correspondence between these 2 or 3 lineages of $T$. cruzi shown by various studies.

Luquetti et al. (1986) reported that 12 isolates from chronic patients in Central Brazil belonged to only $\mathrm{Z} 2$, possibly Group 3 in our study, and more than $80 \%$ of them were from patients with intestinal disorder. This finding appears to indicate the relation of Z2 strain to mega syndrome. However, the following studies mapping clinical syndromes on phylogenetic trees of South American isolates failed to find any phylogenetic correlation (Apt et al. 1987;
Breniere et al. 1989; DeLucad'oro et al. 1993; Henriksson et al. 1993; Lauria-Pires \& Teixeira, 1996; Montamat et al. 1996). If genetic recombination had occurred among these isolates, this might explain the lack of correlation. On a larger geographical scale, we have detected such a correlation: the Central American isolates forming our Group 1 cause only the cardiac form of the disease whereas both the intestinal and cardiac manifestations occur in South America where 2 major strains, Groups 1 and 3, exist. Geographical separation between Central and South America could possibly have prevented genetic recombination across the Isthmus of Panama. Certainly, one very distinct lineage (Group 1) occurs primarily in Central America and should be the focus of further work.

We wish to thank the following for providing isolates of T. cruzi: Professor F. Sendo, Dr T. Yamashita, Dr T. Watanabe, Yamagata University, Japan; Professor J. A. Dvorak, NIAID, USA; Professor T. Takeuchi, Dr S. Miura, Dr T. Nozaki in Keio University, Japan; Dr M. Horio, University of Occupational and Environmental Health, Japan; Dr T. Mimori, Kumamoto University, Japan. We are indebted to Dr D. Blair, James Cook University, Australia for his helpful suggestions and critical reading of the manuscript. This study was supported by Grants-in-Aid for Scientific Research (C) (No. 09670263, 11670243, 12376001) from the Ministry of Education, Science, Sports and Culture of Japan, for International Health Cooperation Research (9C3) from the Ministry of Health and Welfare of Japan, and for medical research from Ohyama Health Foundation.

\section{REFERENCES}

agatsuma, T. \& Habe, s. (1986). Genetic variability and differentiation of natural populations in three Japanese lung flukes, Paragonimus ohirai, Paragonimus iloktsuenensis and Paragonimus sadoensis. Fournal of Parasitology 72, 417-433.

APt, W., AGUilera, x., ARribada, A., GOMEZ, L., Miles, M. A. \& WIDMER, G. (1987). Epidemiology of Chagas' disease in northern Chile: isozyme profiles of Trypanosoma cruzi from domestic and sylvatic transmission cycles and their association with cardiopathy. American Fournal of Tropical Medicine and Hygiene 37, 302-307.

AYALA, F. J. (1993). Trypanosoma and Leishmania have clonal population structures of epidemiological significance. Biological Research 26, 47-63.

Bogliolo, A. R., LAURia-PiREs, L. \& GibSON, w. C. (1996). Polymorphism in Trypanosoma cruzi: evidence of genetic recombination. Acta Tropica 61, 31-40.

breniere, S. F., Carrasco, R., Revollo, S., aparicio, G., desjeux, P. \& Tibayrenc, M. (1989). Chagas' disease in Bolivia: clinical and epidemiological features and zymodeme variability of Trypanosoma cruzi strains isolated from patients. American Fournal of Tropical Medicine and Hygiene 41, 521-529.

BRown, A. H. D., FELdMan, M. W. \& Nevo, E. (1980). Multilocus structure of natural populations of Hordeum spontaneum. Genetics 96, 523-536. 
CARRASCO, H. J., FRAME, I. A., VALENTE, S. A. \& MILES, M. A. (1996). Genetic exchange as a possible source of genomic diversity in sylvatic populations of Trypanosoma cruzi. American Fournal of Tropical Medicine and Hygiene 54, 418-424.

DEleON, M. P., YANAGI, T., KIKUCHI, M., MU, J., AYAU, O., MATTA, V., PAZ, M., JUAREZ, S., KANBARA, H., TADA, I. \& HIRAYAMA, K. (1998). Characterization of Trypanosoma cruzi population by DNA polymorphism of the cruzipain gene detected by single stranded DNA conformation polymorphism (SSCP) and direct sequencing. International Fournal for Parasitology 28, $1867-1874$.

Delucad'oro, G. M., Gardenal, C. N., PERret, B., CRisci, J. V. \& MONTAMat, E. E. (1993). Genetic structure of Trypanosoma cruzi populations from Argentina estimated from enzyme polymorphism. Parasitology 107, 405-410.

DIAS, J. C. P. (1992). Epidemiology of Chagas' disease. In Chagas' Disease (American Trypanosomiasis) : Its Impact on Transfusion and Clinical Medicine (ed. Wendel, S., Brener, Z., Camargo, M. E. \& Rassi, A.), pp. 49-80. ISBT Brazil 1992-Sociedade Brasileira de Hematologia e Hemoterapia.

Felsenstein, J. (1993). PH YLIP, Phylogeny Inference

Package. Version 3.5. Department of Genetics, University of Washington, Seattle.

GOMES, M. L., MACEDo, A. M., PENA, S. D. J. \& CHIARI, E. (1998). Genetic relationships between Trypanosoma cruzi strains isolated from chronic chagasic patients in southern Brazil as revealed by RAPD and SSR-PCR analysis. Acta Tropica 69, 99-109.

Henriksson, J., PETtersson, U. \& solari, A. (1993). Trypanosoma cruzi: correlation between karyotype variability and isoenzyme classification. Experimental Parasitology 77, 334-348.

higo, H., YANAGi, T., MatTa, V., Agatsuma, T., Kanbara, H., TADA, I., DELEON, M. P., MONROY, C. \& TABARU, Y. (1997). Genetic structure of Trypanosoma cruzi in Central America and its comparison with South American strains. International Fournal for Parasitology 27, 1369-1374.

LAURIA-PIRES, L. \& TEIXEIRA, A. R. L. (1996). Virulence and pathogenicity associated with diversity of Trypanosoma cruzi stocks and clones derived from Chagas' disease patients. American Journal of Tropical Medicine and Hygiene 55, 304-310.

LEWICKA, K., BRENIERE-CAMPANA, S. F., BARNABE, C., DEDET, J. \& TIBAYRENC, M. (1995). An isoenzyme survey of Trypanosoma cruzi genetic variability in sylvatic cycles from French Guiana. Experimental Parasitology 81, 20-28.

Lopez-olmos, v., PEREZ-NASSER, N., Pinero, D., ORTEGA, E., HERnANDEZ, R. \& ESPINOZA, B. (1998). Biological characterization and genetic diversity of Mexican isolates of Trypanosoma cruzi. Acta Tropica 69, 239-254.
LUQuetTi, A. O., MIles, M. A., RASSI, A., DEREZENDE, J. M., DesouzA, A. A., POVOA, M. M. \& ROdRigues, I. (1986).

Trypanosoma cruzi: zymodemes associated with acute and chronic Chagas' disease in central Brazil.

Transactions of the Royal Society of Tropical Medicine and Hygiene 80, 462-470.

MAYNARD-SMITH, J., SMITH, N. H., O’ROUREK, M. \& SPRATT, B. G. (1993). How clonal are bacteria? Proceedings of the National Academy of Sciences, USA 90, 4384-4388.

Miles, M. A., APT, W., WIDMER, G., POVOA, M. M. \& SCHOFIELD, C. J. (1984). Isozyme heterogeneity and numerical taxonomy of Trypanosoma cruzi stocks from Chile. Transactions of the Royal Society of Tropical Medicine and Hygiene 78, 526-535.

montamat, E. E., DelucaD'oro, G. M., Gallerano, R. H., SOSA, R. \& BLANCO, A. (1996). Characterization of Trypanosoma cruzi populations by zymodemes: correlation with clinical picture. American Fournal of Tropical Medicine and Hygiene 55, 625-628.

NEI, M. (1987). Molecular Evolutionary Genetics. Columbia University Press, New York.

Oliveira, R. P., BRoude, N. E., MACEDo, A. M., CANTOR, C. R., SMith, C. L. \& PENA, D. J. (1998). Probing the genetic population structure of Trypanosoma cruzi with polymorphic microsatellites. Proceedings of the National Academy of Sciences, USA 95, 3776-3780.

oury, B., DUtrait, N., BASTRENTA, B. \& TiBAYRENC, M. (1997). Trypanosoma cruzi: evaluation of a RAPD synapomorphic fragment as a species-specific DNA probe. Fournal of Parasitology 83, 52-57.

SHAW, C. R. \& PRASAD, R. (1970). Starch gel electrophoresis of enzymes - a compilation of recipes. Biochemical Genetics 4, 297-320.

STEVEns, J. R. \& TIBAYRENC, M. (1996). Trypanosoma brucei s.l.: evolution, linkage and the clonality debate. Parasitology 112, 481-488.

TiBAyrenc, M. (1995). Population genetics of parasitic protozoa and other microorganisms. Advances in Parasitology 36, 47-115.

TIBAYRENC, M. \& AYALA, F. J. (1988). Isozyme variability in Trypanosoma cruzi, the agent of Chagas' disease: genetical, taxonomical, and epidemiological significance. Evolution 42, 277-292.

Tibayrenc, M., KJEllberG, F. \& Ayala, F. J. (1990). A clonal theory of parasitic protozoa: the population structures of Entamoeba, Giardia, Leishmania, Naegleria, Plasmodium, Trichomonas, and Trypanosoma and their medical and taxonomical consequences. Proceedings of the National Academy of Sciences, USA 87, 2414-2418.

Tibayrenc, M. \& Miles, M. A. (1983). A genetic comparison between Brazilian and Bolivian zymodemes of Trypanosoma cruzi. Transactions of the Royal Society of Tropical Medicine and Hygiene 77, 76-83. 